\title{
Evidence discussing glycaemic targets that need to be achieved to reduce macrovascular disease risk in type 2 diabetes
}

\section{Introduction}

Type 2 diabetes mellitus (T2DM) is a disease that causes the glucose (sugar) levels in the blood to rise above normal range. High blood sugar destroys both small (microvascular) and large (macrovascular) blood vessels via a process known as clogging of the vessels (Atherosclerosis). ${ }^{1}$ When clogging occurs in large vessels, it causes the vessels to narrow thereby reducing blood flow to the muscles of the heart, brain and limbs (extremities) resulting in heart attack, stroke, pain and reduced healing of infection and wounds. ${ }^{2}$ People with T2DM have a 2 to 4 - fold increased risk of developing diseases of the large vessels and these diseases of the large vessels account for $70 \%$ deaths in people with T2DM. ${ }^{3}$ This paper thus aims at discussing the disadvantages of high blood sugar and the importance of maintaining a near normal blood sugar level to prevent disease of the large vessels in people with type 2 diabetes (Figure 1).

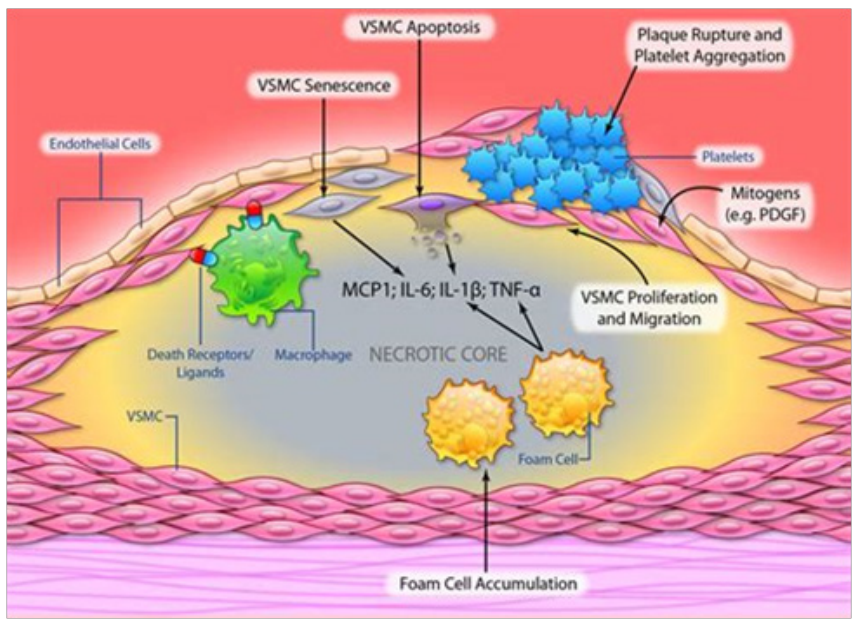

Figure I Necrotic core.

How does non-optimal blood glucose affect the individual with type 2 diabetes?

Non- optimal blood glucose has shown to have a detrimental effect on the patient's daily life. ${ }^{1}$ In patients without diabetes, their blood sugar is usually maintained between $4 \mathrm{mmol} / 1$ to $7 \mathrm{mmol} / 1$. In diabetic individual with poorly managed diabetes, their blood sugar can rise from $10 \mathrm{mmol} / 1$ and above. ${ }^{4}$ High blood sugar together with other risk factors such as high blood pressure, smoking, alcohol, sedentary lifestyle, obesity and high cholesterol levels can further aggravate the clogging process. ${ }^{5}$ This will cause further damage resulting in diseases of the large vessels such as;

Myocardial infarction (heart attack)

Cerebrovascular accident (Stroke)

Peripheral artery disease (diabetic foot ulcers due to reduced blood flow to the extremities)
Volume 6 Issue 3 - 2019

\author{
Rajesh Jain,' Susanne Olejas, ${ }^{2}$ Ani Rashel \\ Feh, ${ }^{2}$ Alexander Edwards, ${ }^{2}$ Ibina Abigo, ${ }^{2}$ \\ Wioleta Zietek, ${ }^{2}$ Zoonifer Khan, ${ }^{2}$ Satrupa \\ Ragoonanan, ${ }^{2}$ Nisha Benoy ${ }^{2}$ \\ 'Diabetes Prevention Control Project, National health Mission, \\ India \\ ${ }^{2}$ World Diabetes Foundation, Denmark
}

\begin{abstract}
Correspondence: Dr Rajesh Jain MD, Project Manager, Diabetes Prevention Control Project, National health Mission with World Diabetes Foundation, Denmark. 108 B Gandhi Gram,Vinobha Nagar, Kanpur, UP, India, Email drrajeshjain@diabetesasia.org
\end{abstract}

Received: May 21, 2019 | Published: August 19,2019

Coronary heart disease. ${ }^{6}$

Diabetic Patients has $25 \%$ lifetime risk of developing foot related complaints $^{7}$ and around $6 \%$ of diabetes people are affected from diabetic foot disease (Figure 2 \& Figure 3 ). ${ }^{8}$

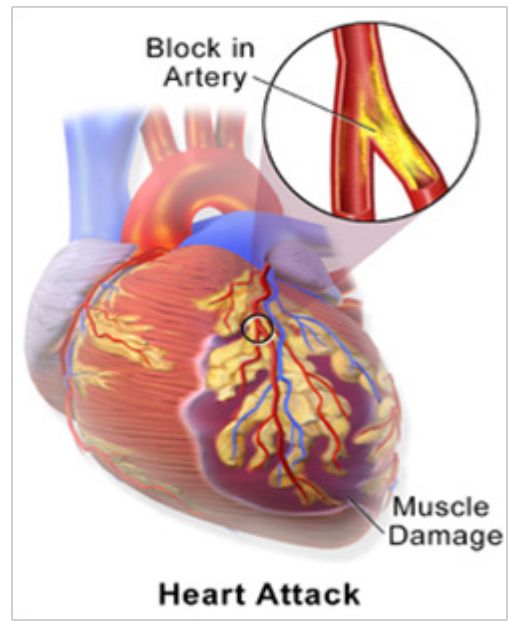

Figure 2 Heart attack.

How does high blood sugar affect the individuals' day to day life?

High blood sugar can have a very negative impact on the day to day life of the individual with type 2 diabetes mellitus. Very high blood sugar is usually associated with symptoms such as:

Recurrent infections

Tiredness

Vision problems

Thirst and hunger ${ }^{9}$ 
When high blood sugar level remains consistently unmanaged over many years, it results in leg ulcers

Lower limb amputation

Swallowing difficulties following a stroke

Pain

Sexual dysfunction

Incontinence

Communication difficulties ${ }^{1,10}$

Emotional distress/depression ${ }^{11}$

Reduced quality of life ${ }^{12}$

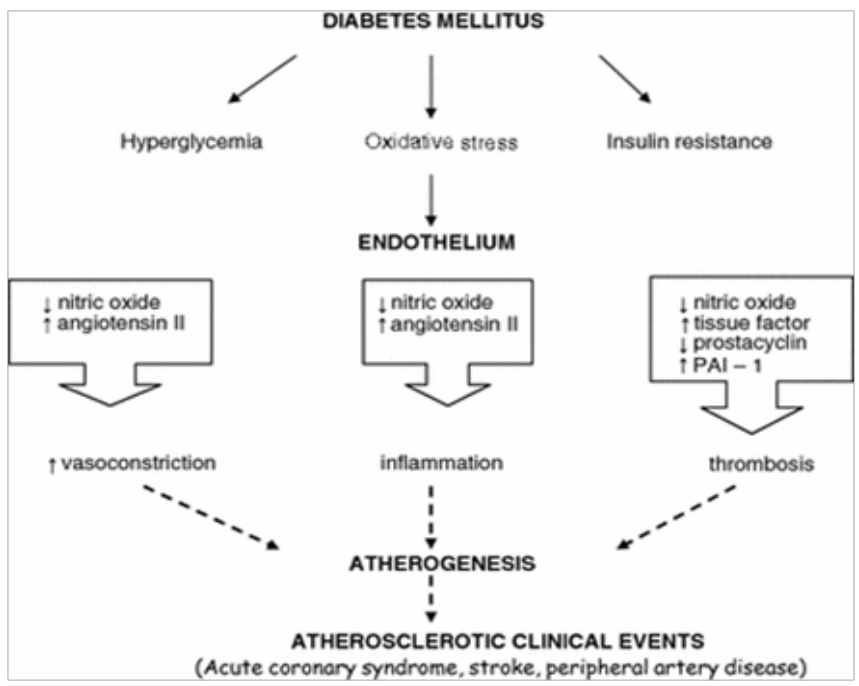

Figure 3 Diabetes mellitus.

\section{What is glycaemic target?}

Glycaemic target is a measurement to determine how effectively an individuals' blood sugar is being managed. Different guidelines have set different targets for people with type 2 diabetes. The following glycaemic targets are recommended by NICE guidelines:

$48 \mathrm{mmol} / \mathrm{mol}(6.5 \%)$ or less for individuals whose diabetes is being managed either with healthy diet, and lifestyle modification (smoke cessation, exercise and alcohol abstinence) or diet, lifestyle changes and a single dose of antidiabetic medication that does not cause the blood sugar levels to drop below $4 \mathrm{mmol} / 1$.

$53 \mathrm{mmol} / \mathrm{mol}(7.0 \%)$ for individuals whose antidiabetic medication can cause their blood sugar levels to drop below $4 \mathrm{mmol} / 1$ and those whose blood glucose level rises to $58 \mathrm{mmol} / \mathrm{mol}(7.5 \%)$ or more despite being on one antidiabetic medication. ${ }^{4} \mathrm{~A}$ less tight glycaemic target of less than $64 \mathrm{mmol} / \mathrm{mol}(8.0 \%)$ may be use for individuals with history of severe low blood sugar, elderly patients, patients with advanced large vessels disease, long duration diabetes in whom glycaemic goal cannot be achieve notwithstanding effective selfmanagement education, proper blood sugar monitoring, and effective management with multiple antidiabetic medication including insulin (ADA, 2015). Lowering blood sugar is critical to T2DM management in order to decrease the risk of large and small vessel disease. Lowering glycaemic target should be tailored to individual needs (Table $1 \&$ Table 2).
Table I Glycaemic targets for the management of type 2 diabetes

\begin{tabular}{llll}
\hline Organization & $\begin{array}{l}\text { HbAlc (\%) } \\
\mathbf{m m o l} / \mathrm{mol}\end{array}$ & $\begin{array}{l}\text { FPG } \\
(\mathbf{m g} / \mathrm{L})\end{array}$ & $\begin{array}{l}\text { PPG } \\
(\mathbf{m g} / \mathrm{L})\end{array}$ \\
\hline NICE & $<6.5(48 \mathrm{mmol} / \mathrm{mol})$ & & $<153$ \\
IDF - EUROPE & $<6.5(48 \mathrm{mmol} / \mathrm{mol})$ & $<100$ & $<140$ \\
ADA - EAC & $<7.0(53 \mathrm{mmol} / \mathrm{mol})$ & $70-130$ & $<180$ \\
AACE & $\begin{array}{l}<\text { or equal } 6.5 \\
(48 \mathrm{mmol} / \mathrm{mol})\end{array}$ & $<110$ & $<140$ \\
\hline
\end{tabular}

Table 2 Glycaemic targets for older adults

\begin{tabular}{lll}
\hline Group & HbAlc $\%$ & $\begin{array}{l}\text { HbAlc mmol/ } \\
\text { mol }\end{array}$ \\
\hline Functionally independent & $7-7.5 \%$ & $53-59$ \\
Functionally dependent & $7-8 \%$ & $53-64$ \\
Frail & Up to $8.5 \%$ & Up to 70 \\
Dementia & Up to $8.5 \%$ & Up to 70 \\
End of life care & Avoid symptomatic low blood sugar
\end{tabular}

\section{Does reduction in glycaemic level reduces the risk of macrovascular complication?}

Several studies have investigated the effect of tight glycaemic control on large vessels disease in individuals with type 2 diabetes. The United Kingdom Prospective Diabetes Study (UKPDS) investigated the effect of intensive glycaemic control on large vessels disease in 3687 newly diagnosed T2DM patients with a glycaemic target of $6.0 \%$. After 10 years follow- up period, a glycaemic level of $7.0 \%$ was attained in the intensive treatment group compared to $7.9 \%$ in the diet group. The intensive treatment group experienced a significant reduction in stroke, heart attack and diabetes related deaths as well as reduction in eye disease, kidney disease and diseases of the lower limbs. Hence supporting glycaemic targets of $7.0 \%$ or less in the prevention of disease of the large vessels (Table 3). ${ }^{13,14}$

The Action to Control Cardiovascular Risk in Diabetes assessed the effect of reducing glycaemic levels to less than $6 \%$ on cardiovascular events in 10,251 T2DM patients at high risk of cardiovascular disease. The patients in the intensive treatment achieved a mean $\mathrm{HbA} 1 \mathrm{c}$ of $6.5 \%$ at six months. The ACCORD study revealed that lower glycaemic levels were related with a reduction in the onset or progression of small vessels disease. Findings from the ACCORD study also suggest that the older adults may require a less stringent glycaemic target(Figure 4 \& Figure 5). ${ }^{15}$

The Action in Diabetes and Vascular Disease (ADVANCE) and the Veteran Affairs Diabetes Trial (VADT) looked at whether reducing glycaemic levels to less than $6.5 \%$ would have any significant effect in reducing both small and large vessels disease. Both ADVANCE and VADT showed that reducing glycaemic levels had significant effect in preventing the progression of small vessel disease but no changes were seen in major cardiovascular events (Figure 6 \& Table 4). ${ }^{16,17}$

\section{The importance of lowering glycaemic target}

Several clinical trials including the UKPDS, ACCORD, ADVANCE and VADT examined whether tight blood sugar levels can reduce the risk of stroke, heart attack and diabetes related deaths 
in individuals with T2DM. The UKPDS demonstrated that optimal glycaemic control significantly reduces the risk of stroke, heart attack, diabetes-related deaths and all other causes of deaths. A tenyear follow-up of the UKPDS continued to show significant benefits in risk reduction in both small and large vessels disease even when
HbAlc had deteriorated later. This is known as the "legacy effect". ${ }^{14}$ Meta-analyses involving 5 studies revealed that lowering glycaemic levels in T2DM patients significantly reduces the occurrence of heart attack and coronary heart disease. ${ }^{18,19}$ Good glycaemic control have also shown to enhance wound healing in individual with T2DM. ${ }^{20}$

Table 3 Findings from the UKPDS

\begin{tabular}{|c|c|c|c|c|}
\hline & \multicolumn{2}{|c|}{ Metformin intensive } & \multicolumn{2}{|c|}{ Sulfonylurea/insulin intensive } \\
\hline & Change in risk & P Value & Change in risk & P Value \\
\hline Stroke & Reduced by $41 \%$ & NS & Increased by $14 \%$ & NS \\
\hline Heart attack & Reduced by $39 \%$ & 0.01 & Reduced by $21 \%$ & NS \\
\hline Diabetes related deaths & Reduced by $42 \%$ & 0.017 & Reduced by $20 \%$ & NS \\
\hline $\begin{array}{l}\text { Other diabetes related } \\
\text { endpoints }\end{array}$ & Reduced by $32 \%$ & 0.0023 & Reduced by $7 \%$ & NS \\
\hline Small vessels disease & Reduced by $29 \%$ & NS & Reduced by $16 \%$ & NS \\
\hline
\end{tabular}

Table 4 Outcomes: summary of ACCORD,ADVANCE andVADT Study

\begin{tabular}{|c|c|c|c|}
\hline & Accord & Advance & Vadt \\
\hline $\mathrm{HbAlc}$ Intensive vs standard & 6.4 VS 7.5 & 6.4 VS 7.0 & 6.9 VS 8.4 \\
\hline $\begin{array}{l}\text { Nonfatal heart attack } \\
\text { Intensive vs standard }\end{array}$ & 3.6 vs 4.6 & 2.7 vs 2.8 & 6.3 vs 6.1 \\
\hline $\begin{array}{l}\text { CV Deaths Intensive vs } \\
\text { standard }\end{array}$ & 2.6 vs 1.8 & 4.5 vs 5.2 & 2.1 vs 1.7 \\
\hline Small vessel disease & & Nephropathy reduced by $21 \%$ Retinopathy reduced by $5 \%$ & \\
\hline Take home & $\begin{array}{l}\text { Reduced } \\
\text { heart attack }\end{array}$ & $\begin{array}{l}\text { Blood sugar had no effect on CV events but reduced the } \\
\text { risk of small vessel disease }\end{array}$ & $\begin{array}{l}\text { Blood sugar control had no } \\
\text { effect on } \mathrm{CV} \text { events }\end{array}$ \\
\hline
\end{tabular}

\section{ACCORD Glucose (Action to Control Cardiovascular Risk in Diabetes - Glucose-lowering arm) \\ To test whether an intensive strategy that targets $\mathrm{HbA}_{1 \mathrm{c}}$ levels $<6.0 \%$ reduces the rate of $\mathrm{CV}$ events more than a standard strategy that targets an $\mathrm{HbA}_{1 \mathrm{c}}$ of $7.0 \%$ to $7.9 \%$ \\ - Population and treatment: \\ 10000 patients with type 2 diabetes and either heart disease or two risk factors for heart disease \\ Randomly assigned to intensive blood sugar lowering or to standard blood sugar lowering \\ - Primary outcome: \\ A composite of fatal and nonfatal major $\mathrm{CV}$ events}

\section{Figure 4 ACCORD Glucose.}

\section{Is glycaemic target individualized or standard for everyone?}

Following findings from UKPDS, ACCORD, ADVANCE and VADT study, guidelines strongly advocates for individualized targets. The ACCORD, ADVANCE and VADT study had elderly patients as well as patients with more than 10 years duration of diabetes. The mortality rate recorded in these studies demonstrate that very tight glycaemic control could be detrimental in the elderly patients and people with very long duration diabetes. ${ }^{21}$ When setting glycaemic targets, guidelines strongly emphasized on individual factors such as

Diabetes duration

Age of the individual

Lifestyle factors (diet, alcohol, exercise levels, smoking status)

The individual's risk of cardiovascular disease

How well the individual is responding to lifestyle changes and existing antidiabetic medication

The individual's current health status. ${ }^{4,13}$

\section{How does an individual know they are on the right glycaemic target?}

Individual with $\mathrm{T} 2 \mathrm{DM}$ can have their $\mathrm{HbA} 1 \mathrm{C}$ monitored every three to six months. The HbA1c gives a record of glycaemic control for the past three months. ${ }^{4}$ The HbAlc will determine if the individual is achieving their glycaemic target. Blood glucose self - monitoring can also be used to determine if an individual is achieving their glycaemic target. However, NICE guidelines do not recommend regular selfblood glucose monitoring for individual with type 2 diabetes except they are receiving insulin therapy, or they are on oral antidiabetic medication that can make them prone to low blood sugar levels. ${ }^{4}$ 


\section{ACCORD Glucose: Results \\ - The median $A_{1 c}$ level achieved in the intensive-treatment group was $6.4 \%$, vs $7.5 \%$ in the standard group \\ - The trial was stopped early because of an excess of three deaths per 1000 participants per year in the intensive group vs the standard group, over an average of four years of treatment \\ Deaths in the two treatment groups at four years

\begin{tabular}{|c|c|c|}
\hline & Standard glycemic control & Intensive gycemic contro \\
\hline Deaths, $n$ & $203(11 / 1000 \mathrm{y})$ & $257(14 / 1000 / y)$ \\
\hline
\end{tabular}

Figure 5 ACCORD glucose results.

\begin{tabular}{|c|c|c|c|}
\hline \multicolumn{4}{|c|}{$\begin{array}{l}\text { Adverse Outcomes: } \\
\text { ACCORD, ADVANCE and VADT }\end{array}$} \\
\hline Intensive vs Std & ACCORD* & ADVANCE & VADT \\
\hline $\begin{array}{l}\text { Severe Hypoglycemia } \\
\text { (\% per yr) }\end{array}$ & $3.0 \mathrm{vs} 1.0$ & 0.7 vs 0.4 & - \\
\hline $\begin{array}{l}\text { Hypoglycemia requiring } \\
\text { assistance }(\% \text { per year })\end{array}$ & 4.6 vs 1.5 & 1.8 vs 0.6 & 2.3 vs 1.1 \\
\hline Weight Gain $>10 \mathrm{Kg}$ & $27.8 \%$ vs $14.1 \%$ & $0.0 \mathrm{vs}-1.0$ & - \\
\hline $\begin{array}{l}\text { Wt gain }(\mathrm{Kg}) \\
\text { Intensive group }\end{array}$ & 3.5 & 0.7 & 6.8 \\
\hline $\begin{array}{l}\text { Increased Mortality } \\
\text { Rosigliatzone? }\end{array}$ & No & No & No \\
\hline
\end{tabular}

Figure 6 Adverse outcomes.

\section{What else can an individual with type 2 diabetes do to minimise the risk of macrovascular complication?}

Studies have shown that smoke cessation can significantly reduce the risk of cardiovascular mortality and events. ${ }^{22}$ People with T2DM who are overweight or obese are advised to lose weight. The Look AHEAD study found that weight reductions of $5-10 \%$ was linked with significant improvements in CVD risk factors, and more improvements were seen with a more substantial weight loss. A $5-10 \%$ reduction in weight correlated to a $6 \mathrm{mmol} / \mathrm{mol}$ decrease in $\mathrm{HbAlc}$, a $5-\mathrm{mmHg}$ decrease in both systolic and diastolic blood pressure, a $0.5 \mathrm{mmol} / 1$ decrease in triglycerides and a $0.293 \mathrm{mmol} / \mathrm{l}$ increase in HDL cholesterol. ${ }^{23}$ Diet modification, such as eating more fruit and vegetables, oily fish, white meat rather than red, nuts and pulses, wholegrains and reducing saturated fats, dairy products, sugar and salt help to reduce the risk factors associated with CVD. ${ }^{24}$ People with T2DM are advised to take at least 150 minutes aerobic exercise weekly. ${ }^{4,25}$ and they should also stay in regular contact with their dietitian who can advise on diet that can reduce their blood sugar and cholesterol levels. They can also attend a structured diabetes education program where they can learn about carbohydrate counting and low glycaemic index diet. ${ }^{4}$ Furthermore, controlling blood pressure below the target of $140 / 80 \mathrm{mmHg}$ with medication such as ACE Inhibitors can reduce the risk of diabetes complications. ${ }^{4}$

\section{Conclusion}

High blood sugars in individuals with T2DM can result in diseases of the large vessels. The primary objective in managing high blood sugar and preventing the risk of large vessels disease is early treatment and reduction in $\mathrm{HbA} 1 \mathrm{c}$ levels to as near normal as is safely possible. Reduction of $\mathrm{HbA1c}$ to individualized safe levels have shown to have long term benefits in reducing the risk of stroke, heart attack and diabetes -related deaths in individuals with T2DM. Beside antidiabetic medications, strategies that reduces blood pressure, cholesterol levels as well as increased physical activity, healthy diet, smoke cessation 
and alcohol abstinence have been effective in reducing $\mathrm{HbA} 1 \mathrm{c}$ levels and preventing diabetes complication in individuals with T2DM.

\section{Acknowledgements}

None.

\section{Conflicts of interest}

The author declares there is no conflicts of interest.

\section{References}

1. Fowler M. Microvascular and Macrovascular Complications of Diabetes. Clinical Diabetes. 2008;26(2):77-82.

2. Khyzha N, Alizada A, Wilson MD, et al. Epigenetics of Atherosclerosis: Emerging Mechanisms and methods. Trends Mol Med. 2017;23(4):332347.

3. Yamagishi S. Cardiovascular disease in recent-onset diabetes mellitus. $J$ Cardiol. 2011;57(3):257-262.

4. National Institute of Health and Care Excellence. Type 2 diabetes in adults: management. 2017.

5. Han R, Yang W, Dan Yang, et al. Analysis of Status and Risk Factors for Macrovascular Complications in Type 2 Diabetes Mellitus. International Journal of Clinical and Experimental Medical Sciences. 2018;4(3):3945.

6. Beckman J, Creager M. Vascular Complications of Diabetes. Circulation Research. 2016;118(11):1771-1785.

7. Boulton AJ, Vileikyte L, Ragnarson Tennvall G, et al. The global burden of diabetic foot disease. Lancet. 2005;366(9498):1719-1724.

8. Zhang P, Lu J, Jing Y, et al. Global epidemiology of Diabetic foot ulceration: a systematic review and meta-analysis. Ann Med. 2017;49(2):106-116.

9. National Health Service. Hyperglycaemia (High blood sugar). 2019.

10. National Stroke Foundation. Effects of stroke. 2018.

11. Nefs G, Pouwer F, Denollet J, et al. Psychological risk factors of micro- and macrovascular outcomes in primary care patients with type 2 diabetes: rationale and design of the DiaDDZoB Study. BMC Public Health. 2010;10:388

12. Tusek Bunc K, Petek D. Comorbidities and characteristics of coronary heart disease patients: their impact on health-related quality of life. Health and Quality of Life Outcomes. 2016;14(1):159.
13. American Diabetes Association. Glycaemic targets. Diabetes Care. 2015;38(Supply 1):33-40.

14. Effect of intensive blood-glucose control with metformin on complications in overweight patients with type 2 diabetes (UKPDS 34). Lancet. 1998;352(9131):854-865.

15. Gerstein H, Miller M, Byington R, et al. Effects of Intensive Glucose Lowering in Type 2 Diabetes. N Engl J Med. 2008;358(24):2545-2559.

16. ADVANCE Collaborative Group, Patel A, MacMahon S, et al. Intensive Blood Glucose Control and Vascular Outcomes in Patients with Type 2 Diabetes. N Engl J Med. 2008;358(24):2560-2572.

17. Duckworth W, Abraira C, Moritz T, et al. Glucose control and vascular complications in veterans with type 2 diabetes. $N$ Engl $\mathrm{J} \mathrm{Med}$. 2009;360(2):129-139.

18. Mannucci E, Monami M, Lamanna C, et al. Prevention of cardiovascular disease through glycemic control in Type 2 diabetes: A meta-analysis of randomized clinical trials. Nutr Metab Cardiovasc Dis. 2009;19(9):604612.

19. Ray K, Seshasai K, Wijesuriya S, et al. Effect of intensive control of glucose on cardiovascular outcomes and death in patients with diabetes mellitus: a meta-analysis of randomized controlled trials. Lancet. 2009;373(9677):1765-1772.

20. Peppa M, Stavroulakis P, Raptis SA. Advanced glycoxidation products and impaired diabetic wound healing. Wound Repair Regen. 2009;17(4):461-472.

21. Skyler JS, Bergenstal R, Bonow RO, et al. Intensive glycemic control and the prevention of cardiovascular events: implications of the ACCORD, ADVANCE, and VA Diabetes Trials: a position statement of the American Diabetes Association and a Scientific Statement of the American College of Cardiology Foundation and the American Heart Association. Diabetes care. 2009;32(1):187-192.

22. Al Delaimy WK, Manson JE, Solomon CG, et al. Smoking and risk of coronary heart disease among women with type 2 diabetes mellitus. Arch Intern Med. 2002;162(3):273-279.

23. Wing RR, Lang W, Wadden TA, et al. Benefits of Modest Weight Loss in Improving Cardiovascular Risk Factors in Overweight and Obese Individuals with Type 2 Diabetes. Diabetes Care. 2011;34(7):1481-1486.

24. Diabetes UK. Eating for diabetes and heart health. 2019.

25. Buse JB, Ginsberg HN, Bakris GL, et al. Primary prevention of cardiovascular diseases in people with diabetes mellitus: a scientific statement from the American Heart Association and the American Diabetes Association. Diabetes Care. 2007;30(1):162-172. 